\title{
A peptide carrier with a built-in vaccine adjuvant - Construction of immunogenic conjugates
}

Krikorian Dimitrios, Eugenia Panou-Pomonis, Chryssa Voitharou, Constantinos Sakarellos and Maria Sakarellos-Daitsiotis

List of contents:

Figure 1. Schematic representation of the synthesis of the Ac-IL-1 $\beta-\mathrm{SOC}_{4}-\mathrm{Ac}_{4}-\mathrm{TT}-\mathrm{NH}_{2}$ carrier (1).

Figure 2. Schematic representation of the synthesis of the Ac-IL-1 $\beta-\mathrm{SOC}_{4}-\left[\mathrm{Ac}_{4}-(\mathrm{La} / \mathrm{SSB})_{2}-\right.$ TT- $\mathrm{NH}_{2}$ conjugate (3).

Figure 3. LC and ESI-MS of the purified Ac-IL-1 $\beta-\mathrm{SOC}_{4}-\mathrm{Ac}_{4}-\mathrm{TT}-\mathrm{NH}_{2}$ carrier (1). Eluent A $0.1 \%$ TFA in $\mathrm{H}_{2} \mathrm{O}$, eluent B $0.1 \%$ TFA in acetonitrile, linear gradient from $20 \%$ to $50 \%$ eluent B. $\mathrm{M}+\mathrm{H}^{+}$calculated/found 3181.5/3181.6.

Figure 4. LC and ESI-MS of the purified Ac-IL-1 $\beta-\mathrm{SOC}_{4}-\mathrm{Sm}_{4}-\mathrm{TT}-\mathrm{NH}_{2}$ conjugate (2). Elution conditions as in figure 3. $\mathrm{M}+\mathrm{H}^{+}$calculated/found 5940.95/5940.90.

Figure 5. LC and ESI-MS of the purified Ac-IL-1 $\beta-\mathrm{SOC}_{4}-\left[\mathrm{Ac}_{4}-(\mathrm{La} / \mathrm{SSB})_{2}-\mathrm{TT}_{-} \mathrm{NH}_{2}\right.$ conjugate (3). Eluent A $0.1 \%$ TFA in $\mathrm{H}_{2} \mathrm{O}$, eluent B $0.1 \%$ TFA in acetonitrile, linear gradient from $20 \%$ to $40 \%$ eluent $\mathrm{B}$. $\mathrm{M}+\mathrm{H}^{+}$calculated/found $7619.43 / 7619.65$. 


\section{Figure 1}

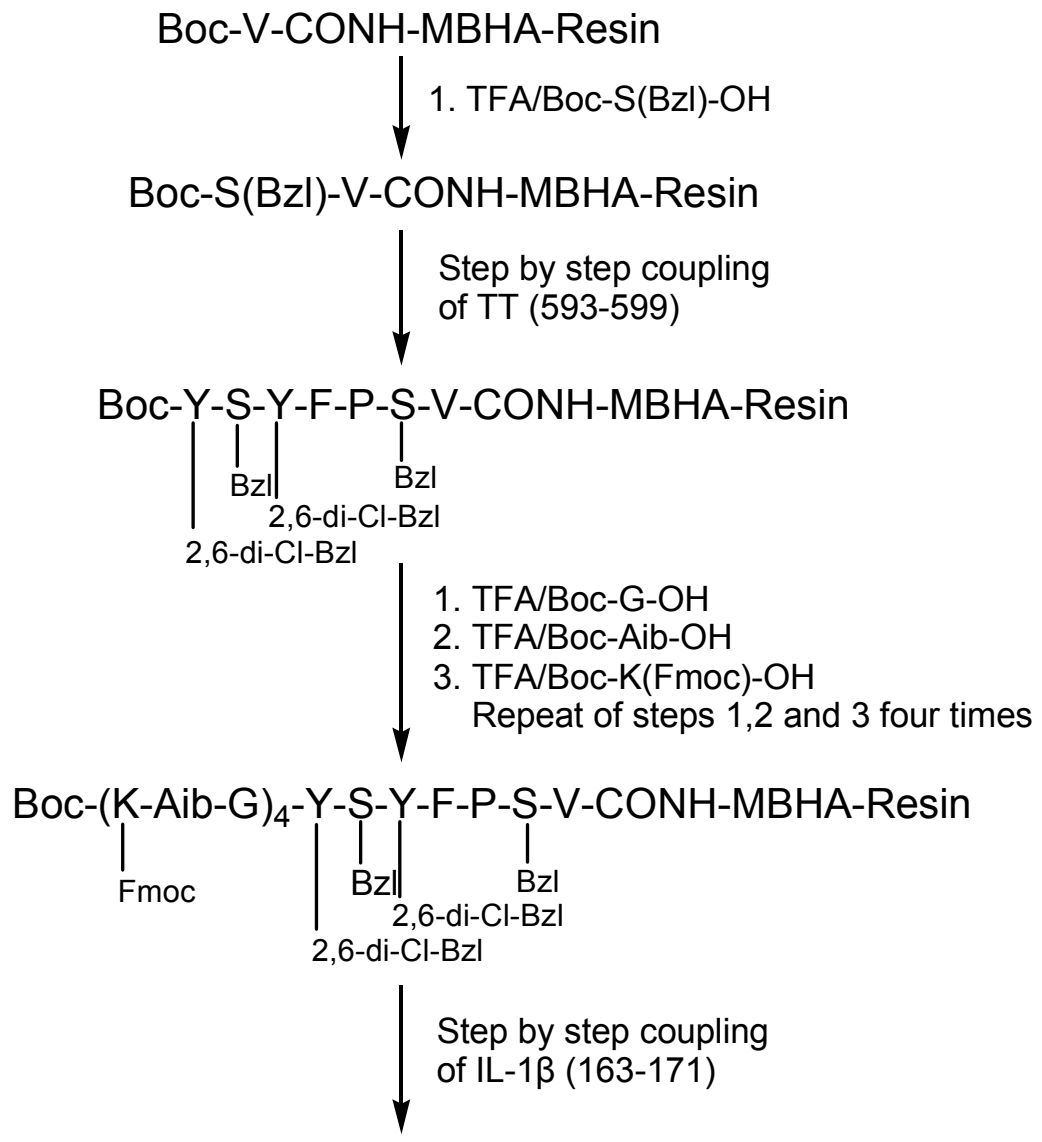
Boc-V-Q-G-E-E-S-N-D-K-(K-Aib-G) ${ }_{4}$-Y-S-Y-F-P-S-V-CONH-MBHA-Resin

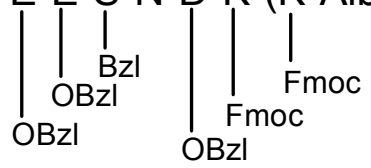

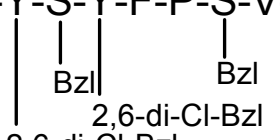
Boc cleavage, TFA
2. $\mathrm{N}^{\mathrm{a}}$-acetylation, $\mathrm{Ac}_{2} \mathrm{O}$

Ac-V-Q-G-E-E-S-N-D-K-(K-Aib-G) $)_{4}$-Y-S-Y-F-P-S-V-CONH-MBHA-Resin

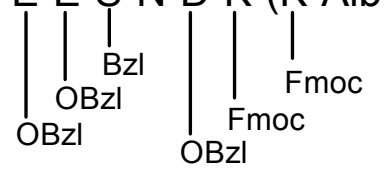

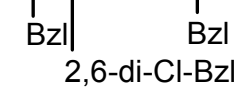
2,6-di-Cl-Bzl
1. Fmoc cleavage, piperidine/DMF
2. $\mathrm{N}^{\varepsilon}$-acetylation, $\mathrm{Ac}_{2} \mathrm{O}$

Ac-V-Q-G-E-E-S-N-D-K-(K-Aib-G) $)_{4}$-Y-S-Y-F-P-S-V-CONH-MBHA-Resin

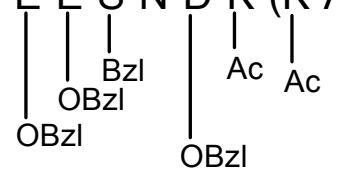

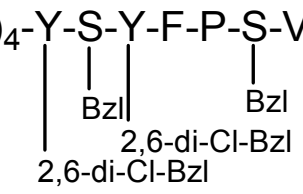

Cleavage from resin $\mathrm{HF}, 1.5 \mathrm{~h}$

Ac-VQGEESNDK-(K-Aib-G) $)_{4}-Y S Y F P S V-C O N H 2$ 


\section{Figure 2}
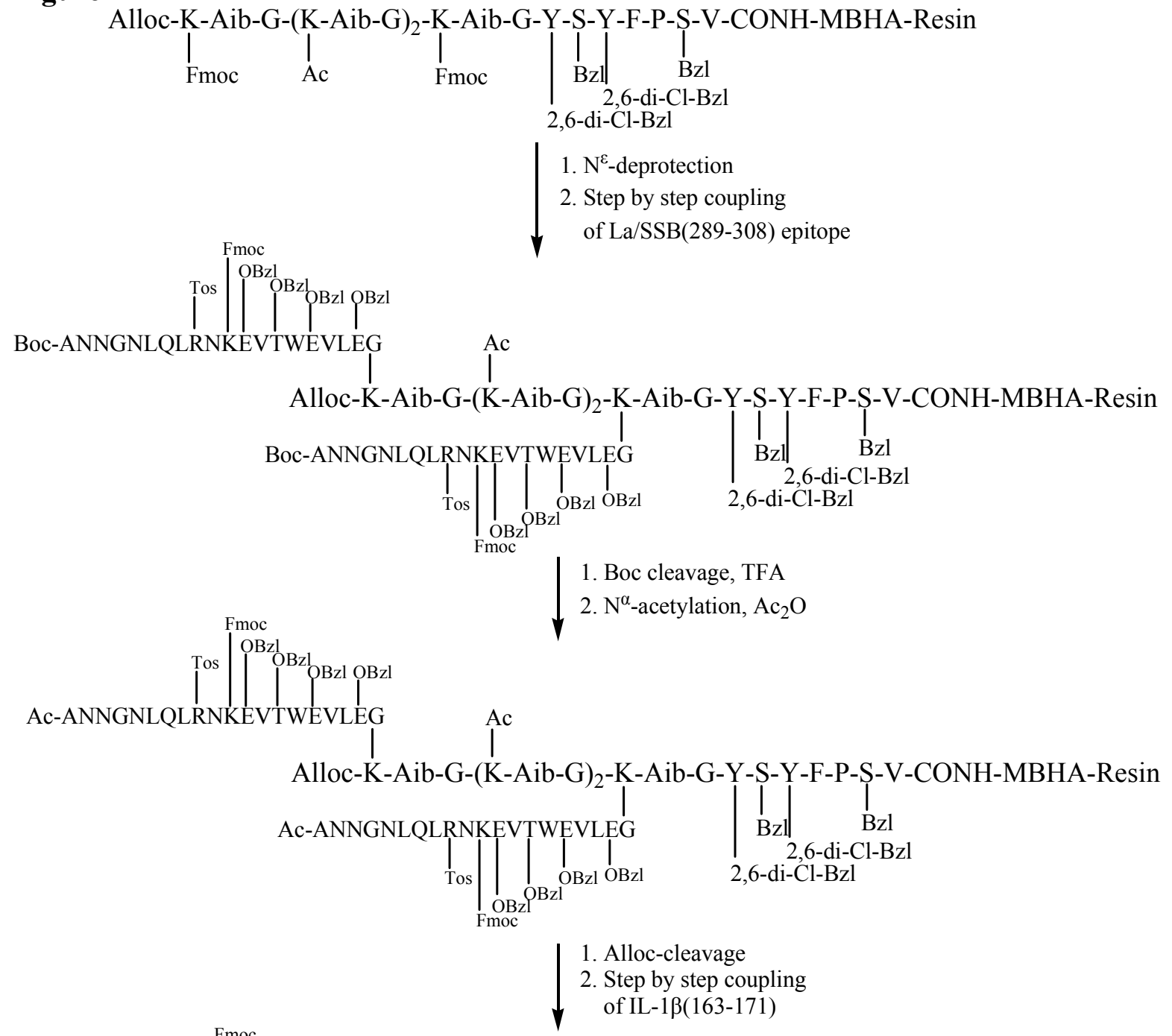

Ac-ANNGNLQLRNKEVTWEVLEG

2. Step by step coupling

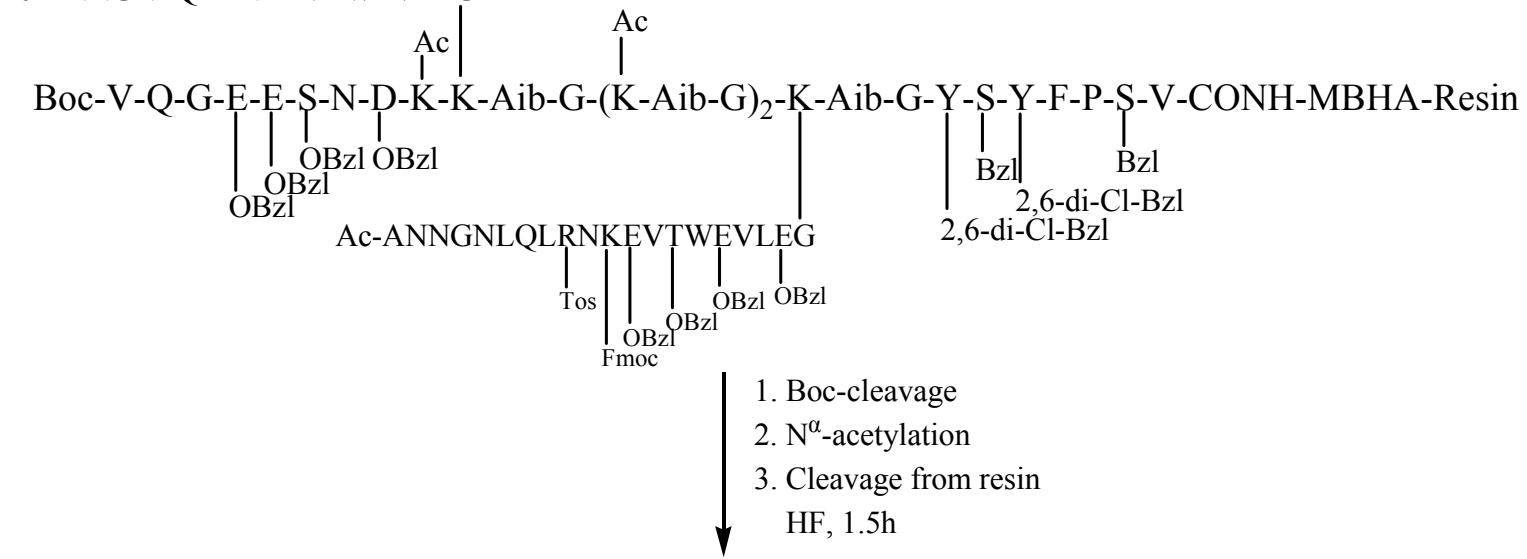
Ac-ANNGNLQLRNKEVTWEVLEG

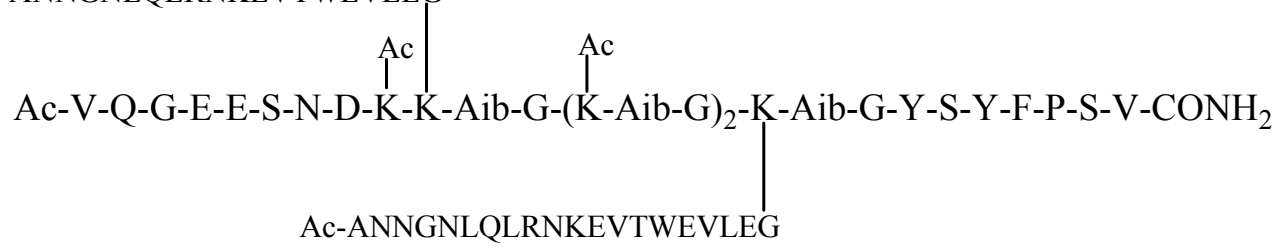


Figure 3
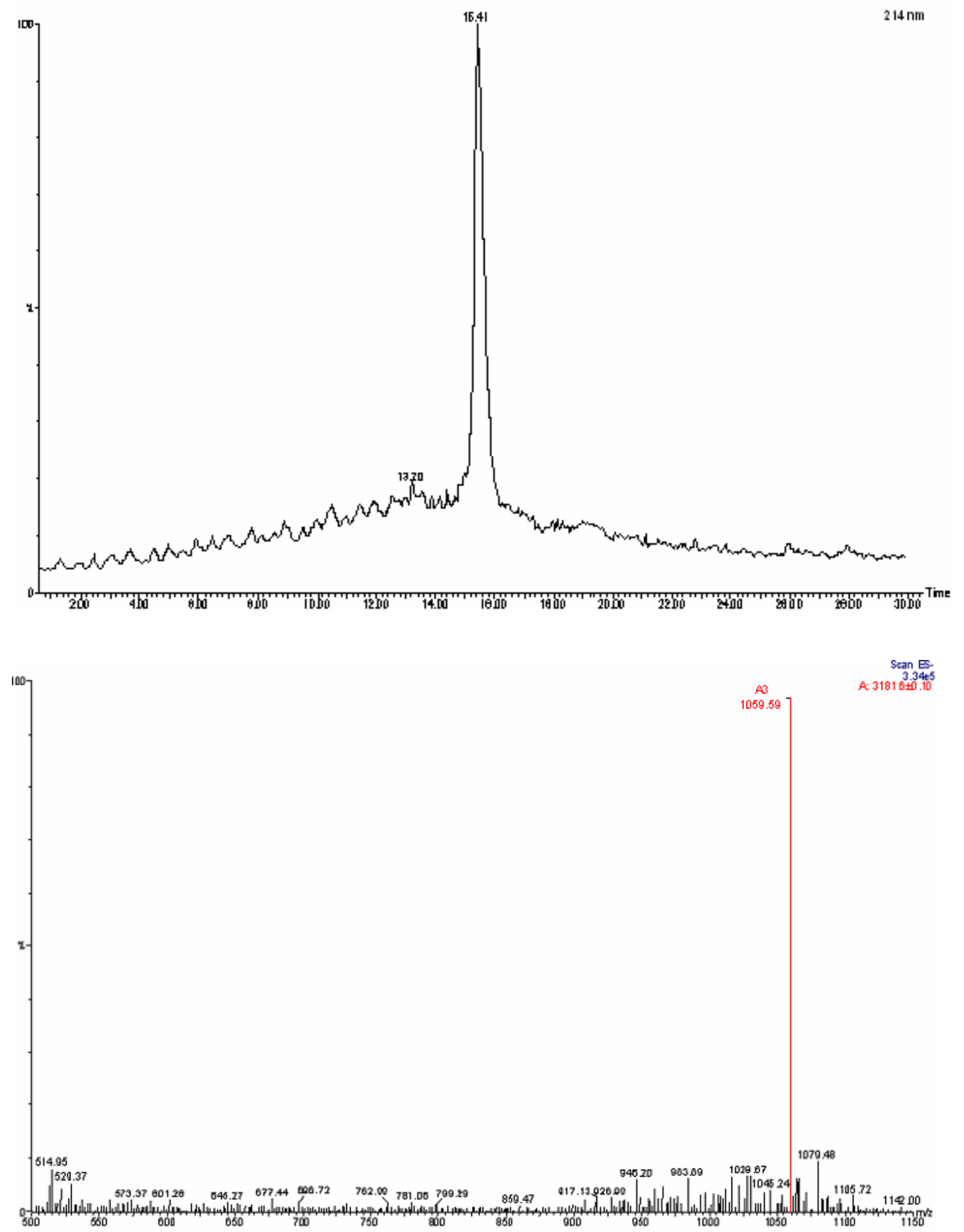
Figure 4
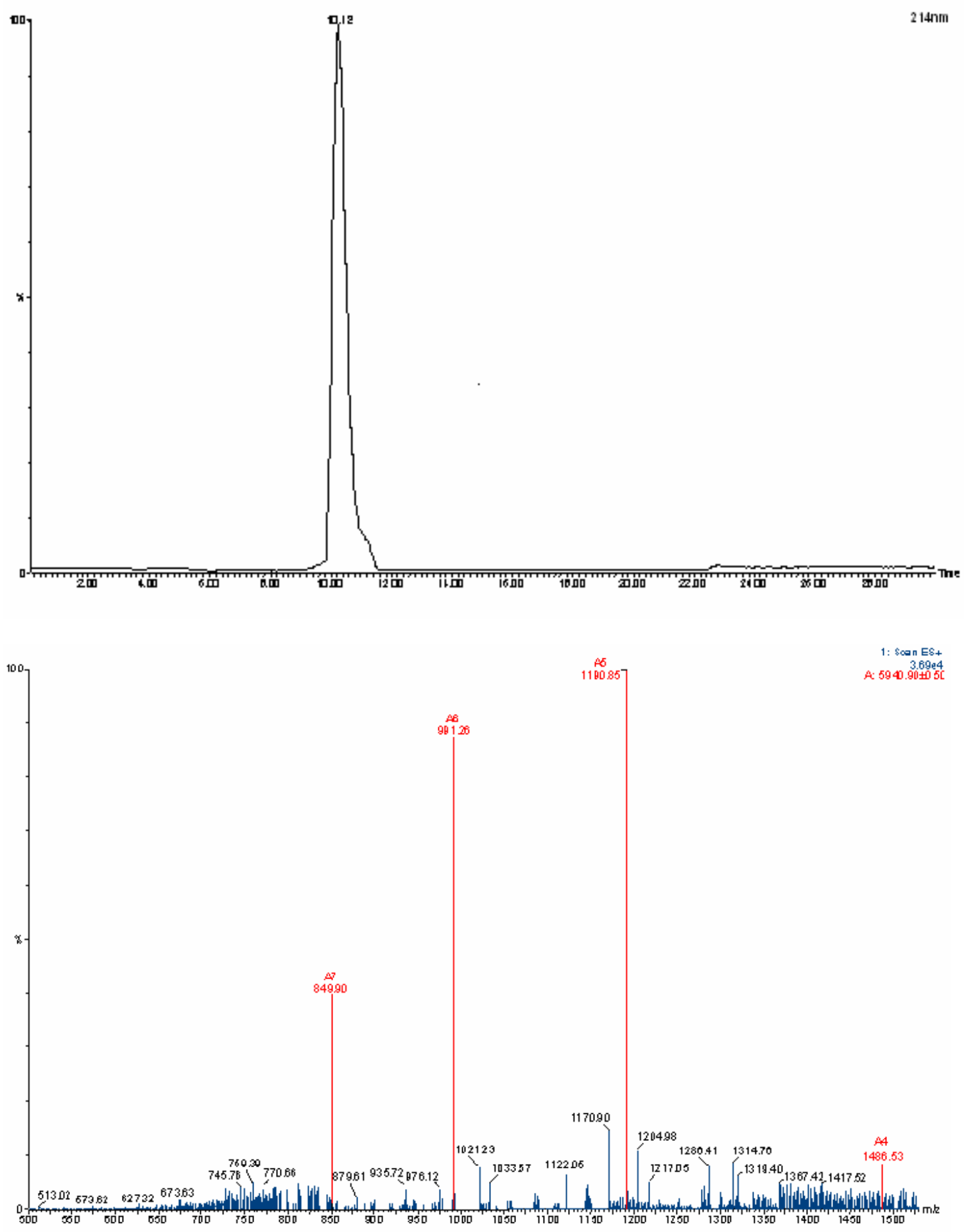


\section{Figure 5}
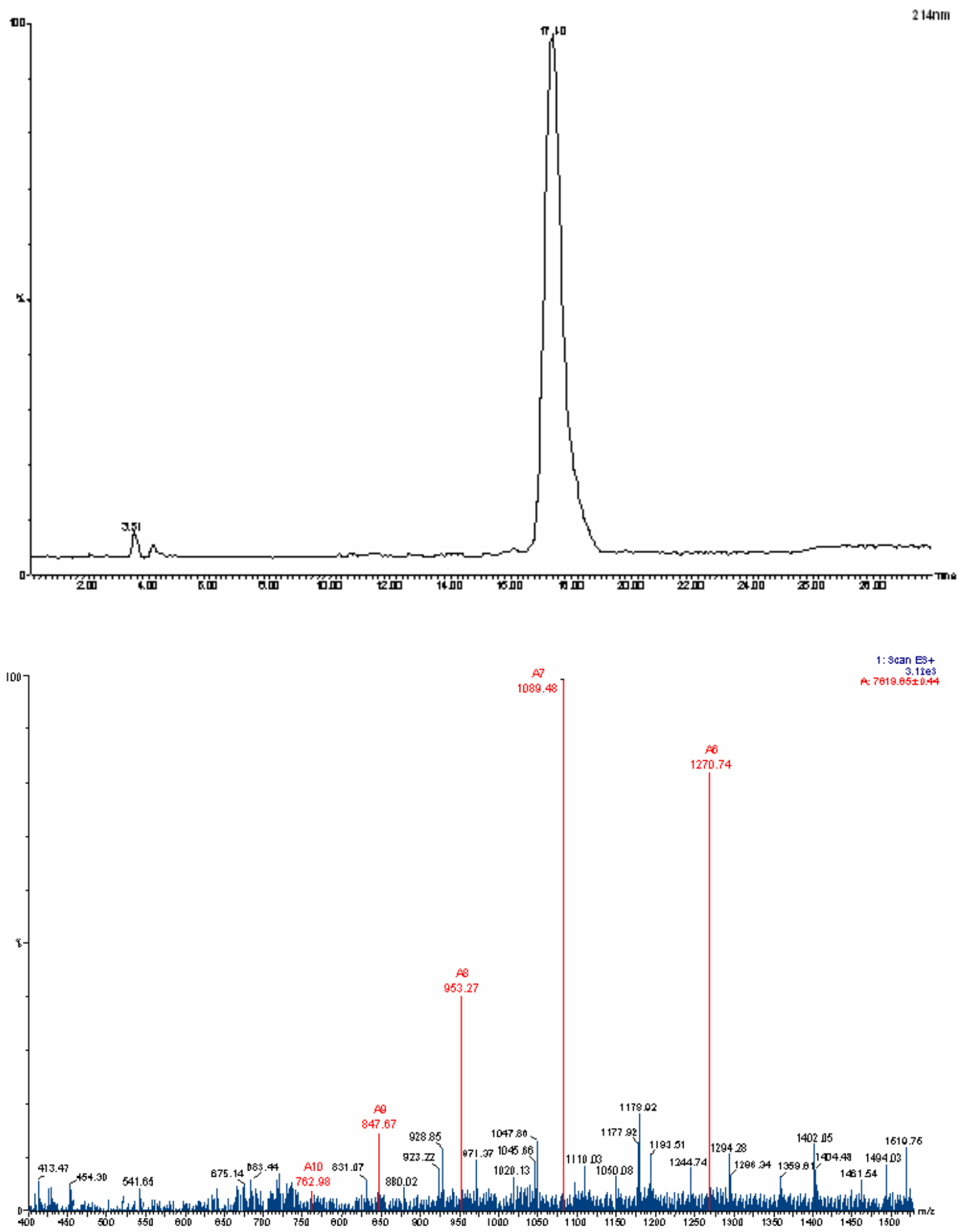